\section{FUNDAMENTOS IDEOLÓGICOS DE NUESTRA HISTORIA REPUBLICANA *}

\section{Carlos Mario Molina Betancur ${ }^{* *}$ Universidad de Medellín}

Fecha de recepción: 1 de junio de 2009

Fecha de aceptación: 15 de junio de 2009

"El pueblo colombiano vive bajo estado de esclavitud, bajo el yugo, no sólo de los alcaldes y curas de las parroquias, sino también bajo el de los tres o cuatro magnates en cada una de ellas (...)

la libertad y las garantías son sólo para aquellos hombres y para los ricos y nunca para los pueblos, cuya esclavitud es peor que la de los mismos indios; que esclavos eran bajo la Constitución de Cúcuta y esclavos quedarían bajo cualquier otra Constitución, así fuera la más democrática (...)

en Colombia hay una aristocracia de rango, de empleo y de riqueza equivalente, por su influjo, pretensiones y peso sobre el pueblo, a la aristocracia de títulos y nacimientos aún la más despótica de Europa (...) en esa aristocracia entran también los clérigos, los frailes, los doctores o abogados, los militares y los ricos, pues aunque hablan de libertad y de garantías,

Artículo resultado de la investigación "Bicentenario constitucional colombiano, 1810-2010. Realizada entre las Universidades de Medellín, Manizales, Libre de Bogotá y Militar Nueva Granada. Terminada en junio 2009.

** Doctor en Derecho Público Interno, por la Universidad Pantheón-Assas-Paris II, Francia, Master en Derecho Público Europeo, por la Academia de Derecho Público de Spetses, Grecia, y Especialista en Derecho Administrativo y en Derecho Constitucional por la Universidad Pantheón-Assas-Paris II, Francia, obtuvo un Diploma de Estudios de Profundidad en Derecho Público Interno, por la misma universidad.

Profesor de tiempo a nivel maestría por la Universidad de Medellín, docente de la Universidad el Rosario, así como de la Maestría en Derecho Administrativo. Ha sido profesor invitado por la Universidad de Nanterre-Paris X, Francia, en el Senado Francés, en la Universidad Rey Juan Carlos I, en Madrid, España, entre otras. Asimismo, ha sido conferencista en la Universidad Nacional Autónoma de México, en el Colegio Superior de Francia, en Lyon, en la Diputación de Córdoba, España, entre otras más. Correo electronico: cmolina@udem.edu.co es para ellos solos que las quieren y no para el pueblo, que, según ellos, debe continuar bajo su opresión

quieren también la igualdad, para elevarse y aparearse con los más caracterizados, pero no para nivelarse ellos con los individuos de las clases inferiores de la sociedad: a éstos los quieren considerar siempre como sus siervos a pesar de todo su liberalismo"

Simón Bolivar

\section{Resumen}

Colombia cuenta, desde 1821, con unos claros fundamentos ideológicos que fundan el Estado social de derecho, consagrado en la Constitución de 1991.

La libertad, la igualdad, la justicia, la moralidad pública y la educación son los pilares fundamentales que soportan nuestras instituciones desde hace ya casi dos siglos. Estos ideales no han podido ser desarrollados adecuadamente y por ello siguen vigentes cuando se habla de un Estado social democrático, con división de poderes y una adecuada reforma agraria.

\section{Palabras clave}

Democracia, Estado social de derecho, libertad, igualdad, justicia, moralidad y educación.

\section{IDEOLOGICAL FOUNDATION OF OUR REPUBLICAN HISTORY}

\begin{abstract}
Colombia has, since 1821, with a clear ideological basis that the rule of law enshrined in the Constitution of 1991.

Freedom, equality, justice, public morality and education are the pillars that support our institutions for almost two centuries. These ideals have not been adequately developed and therefore are still valid when one speaks of a social democratic state with separation of powers and a proper land reform.
\end{abstract}

\section{Keywords}

Democracy, rule of law, freedom, equality, justice, morality and education. 


\section{INTRODUCCIÓN}

¿Qué sería de América Latina sin Simón Bolívar? Bolívar es para América Latina lo que Cervantes ha sido para España: el representante de una sociedad, el "hombre de las dificultades" que le dio sentido a la libertad de un pueblo. Con sus ideas, Simón Bolívar generó una fuerza emblemática de libertad, con una lucha sin tregua ante el despotismo y la adversidad (MIJARES, 1998).

Esto en una época en donde predominaban tres corrientes de ideología política: la conservadora, opuesta a la independencia y favorable al régimen monárquico; la liberal, contraria al gobierno de turno pero partidaria de un cambio progresivo sin rupturas brutales; y la radical, liderada por el Libertador, quien considera de toda lucha por el cambio es justificable si se vive bajo la opresión y la injusticia.

Pero, prudente es preguntarnos desde ahora, ¿qué es una ideología política? En el reciente libro sobre la historia de las ideologías políticas, (MOLINA y OTROS, 2008) el historiador Eduardo Domínguez, establecía que las ideologías políticas son un ingrediente de la naturaleza humana, un sistema de ideas que hacen parte de la estructura mental de un pueblo.

Por ello, las ideologías permiten a las personas, como miembros de un grupo, organizar la multitud de creencias sociales acerca de lo que sucede, y actuar en consecuencia. En la mayoría de los casos sirven a los intereses materiales y simbólicos de un grupo, permitiendo a una persona, o grupo, formarse una percepción del mundo, con base en argumentos específicos y explicaciones sobre un orden social particular. Su sólida argumentación científica es lo que la puede diferenciar de las creencias populares y de los mitos.

Ahora, podemos preguntarnos i Para qué sirve una ideología? Siguiendo el texto en mención, tenemos varias utilidades que le dan a las ideologías:

- Conjunto de ideas que permiten legitimar un poder político dominante.
- Aquello que facilita la toma de posición de un tema determinado.

- Identidad social de un individuo o grupo.

- Medio por medio del cual los agentes sociales de un grupo le dan sentido a su mundo.

- Conjunto de creencias sociales orientadas a la acción.

- Proceso por medio del cual la vida social se convierte en realidad natural.

En el mundo de principios del siglo XIXI, las ideologías más conocidas fueron:

- El liberalismo

- El Conservatismo

- La revolución

- El republicanismo

- El constitucionalismo

En Colombia, las de más relevancia en el debate político eran:

- El liberalismo

- El Conservatismo

- La revolución

Para 1810, Bolívar era un pequeño burgués que se levantaba contra todo un sistema. Lo más conmovedor de la historia del Libertador, es la de la tenacidad de lucha de un hombre solo contra el mundo: un mundo injusto y desigual. Para la época, el absolutismo configura un orden consecuencial en América, no existía allí ni libertad de pensamiento ni libertad de expresión; dos instancias que emanaban del rey se ocupaban de no dejar desarrollar estas libertades en el pueblo: la censura civil y administrativa, y la censura religiosa (SALCEDO, 1982). Pero el caudillo de América tuvo desde muy joven la convicción de que las cosas cambiarían radicalmente y que él dirigiría un ejército glorioso que de la nada lo haría todo ; quien llevó a cuesta la idea de una república libre y diferente a todas las que se conocían en la época, tal vez la libertad la llevaba solamente en su corazón, pero cuya dimensión política se llega a manifestar impecablemente ahora dos siglos después de su constitución. (POLANCO, 1997). 
¿Pero de dónde le venían estas ideas a Bolívar? Mucho se ha escrito al respecto. Se sabe que tuvo una variada influencia para la realización de su obra social. Su sangre y vivencias europeas lo impregnan de un gran sentimiento de justicia y de libertad. Recién pasada la revolución francesa vive en Francia y conoce la gloria del Emperador Napoleón, al que pudiendo imitar, solo extrajo su visión del mundo y de la organización del poder. Igualmente, leyó a grandes filósofos y se entrevistó con grandes estadistas. Por ello, no podemos decir que Simón Bolívar se nutrió de una sola corriente filosófica, su formación y su conocimiento sobre diferentes campos del saber y las civilizaciones de la época lo hacen un hombre educado y bien formado para gobernar. De acuerdo también está la doctrina que lo ha estudiado en el hecho de que el Libertador jamás copió o aplicó esquemas extranjeros, siempre tuvo en consideración el medio social.

Esta originalidad queda gravada en múltiples correspondencias, en los que expresa que las leyes deben ser propias para el pueblo que las vive. Por ello, en acuerdo con la filosofía griega, el Libertador cree que las leyes deben ser relativas a lo físico del país, a su clima, a la calidad del terreno, a su situación económica y política, a su extensión, a su cantidad de habitantes, a la religión de los habitantes, a su pasado, a sus riquezas, a su comercio, a sus costumbres, y hasta relativas a sus modales.

En cuanto a las ideas, el Libertador tomó de un lado y de otro para crear su propio modelo. De Grecia, por ejemplo, tomó su Areópago, y la idea brillante de los guardianes de las costumbres y de las leyes. De Roma tomó sus censores y sus tribunales domésticos. De Esparta, tomó sus austeros establecimientos, para darle a la República un espíritu público, con buenas costumbres y una adecuada moral tanto administrativa como política.

Tres escuelas se deslindan entonces del estudio del pensamiento bolivariano: la militar, la institucional y la ideológica. Esta última, la menos estudiada y puesta en práctica.

\section{EL PENSAMIENTO REVOLUCIONARIO DE BOLIVAR}

\section{A. Un legado de libertad}

Para el Libertador La libertad, es el único objeto digno del sacrificio de la vida de los hombres. La libertad fue el primer móvil de la acción revolucionaría de este genio americano, pero sabía sin duda alguna, que ésta no era completa sino venía acompañada de la educación, la justicia social y una acrisolada moral que convierta en integral la obra del estadista. Conducir masas era, para la época, tarea fácil o relativamente fácil, pero hacerlo con acierto era obra de titanes, y es precisamente allí en donde radica la grandeza del político.

Hay líderes inteligentes y honestos, pero desafortunadamente son pocos, abundan por el contrario los politiqueros: "figuras de arena», prefabricadas por la propaganda de los medios de comunicación, y por ende, sin asideros en la historia de los pueblos, son los que nacen de un momento a otro, generalmente sin preparación, aprovechando la oportunidad del momento, para luego pasar a la historia de olvido estatal. Por ello, si el amor por la libertad llevó a Bolívar a recorrer con sus soldados una superficie latinoamericana mayor en tamaño a la Europa Occidental, sus leyes y decretos tampoco se circunscribieron a un pedazo de este territorio; cubrieron todas las repúblicas creadas por él, especialmente lo inherente a educación y a la moral, pues sabía que sin estos elementos, la independencia no perduraría o corría el riego de no ser completa: «Sin moral Republicana no podía existir gobierno libre».

Por esta razón, Bolívar insiste en el alcance efectivo de los principios. Para el libertador la libertad no debe ser un sofisma, debe ser práctica; es decir que no es otra cosa que en la administración de la justicia y del cumplimiento de las leyes. Pero, el Libertador era consciente de que este principio fundador era difícil mantenerlo en equilibrio, aun en las naciones más cultas y civilizadas. De allí su preocupación por la for- 
mación educativa y ética del ciudadano. En las acciones y resultados de ese difícil tiempo dejó una elocuente enseñanza: «la República cae porque el pueblo no la defiende, y no la defiende porque no la ama». Esto tenía mucho de lógico, si tenemos en cuenta que el pueblo de entonces no podía amarla porque nunca la había vivido, hasta entonces los ciudadanos no existían, al menos en las bajos estratos sociales, que eran la inmensa mayoría de la población. La libertad en la época se había vivido como un juego de palabras sin ningún contenido práctico y concreto.

\section{B. Un legado de igualdad}

Si por algo se le recuerda a Simón Bolívar es por su gran anhelo de igualdad entre los ciudadanos. Para la época, la Revolución se opone a una estructura desigual y esclavista. En América, sin excepción, la situación era la misma, por ello el anhelo igualitario del libertador fue siempre incansable; su deseo más profundo, después de liberar a los pueblos del yugo español, era la abolición de la esclavitud. Esta práctica ancestral era para el Libertador contraria a la humanidad, como contrario era de igual manera el pago del tributo de los indios, a los cuales, sin una justificada causa, se les privaba de propiedades y medios para subsistir.

Por ello se debe resaltar acá la importancia de la primera revolución del Libertador, en donde en un primer gobierno caraqueño suprimió los fueros, exenciones y privilegios con que contaban ciertos sectores de la sociedad. Con esto, las distinciones y títulos hereditarios también fueron anulados; igualmente la preposición «De» en los apellidos, los tratamientos de favor, y las menciones de «su merced» y su señoría. Es cierto que este primer gobierno revolucionario no prohibió ni la esclavitud, ni el tráfico humano, pero si logró decretar tiempo después la prohibición de introducir negros africanos en Venezuela.

Fue solamente hasta su llegada a Margarita en 1816, cuando el 23 de mayo desde la Villa del Norte, anuncia su profunda convicción de terminar con la esclavitud.
En Carúpano determina que no habría más esclavos en Venezuela, allí decretó la libertad absoluta de los que habían sufrido bajo el yugo español en los tres siglos pasados. Con esto, Bolívar establece dos tipos de revolución: una social, al darle la libertad a los que no la tenían y otra económica, al repartir entre los revolucionarios combatientes.

\section{Un legado de Justicia}

Bolívar se preocupa más por liberar los pueblos oprimidos que por entregarles una justicia eficiente y transparente. Tal vez, él era consciente de que lo primero que necesitaba un sistema judicial era la independencia del gobierno, una vez obtenida esta, se debía trabajar por equilibrar los derechos de los ciudadanos. Para ello, como lo vimos anteriormente, la libertad de los indígenas constituye uno de los pilares fundamentales del nuevo sistema de justicia impuesto por el Libertador.

Es por esta razón que tanto en Angostura como en Bolivia, el Libertador propone a la justicia como un poder, y no solamente como una autoridad, como ha sido el caso de Francia y España, desde siglos ancestrales. Para el nuevo continente la justicia debía ser un Poder, un poder Judicial independiente, estable y transparente. Según Bolívar, el pueblo debía presentar sus candidatos, y era el poder legislativo quien debería escoger los individuos que debían componer los Tribunales. Para el Libertador, si el poder judicial no emana de este tipo de origen, era casi imposible conservar su pureza institucional y la protección de los derechos individuales.

\section{Un legado de moralidad pública}

Uno de los legados más importantes que nos deje el pensamiento ideológico del Libertador es la virtuosidad con la cual concebía el poder público. En efecto, el poder moral de la república bolivariana, era uno de los pilares en los que se apoyaba el Estado republicano de 1821 y todos los gobiernos que le siguieron. El mismo Libertador dio el ejemplo: «...El Libertador no re- 
dactaba un proyecto de ley sin tomar en consideración la realidad social del lugar donde iba a ser aplicado, $y$ si bien tuvo influencias extracontinentales y de civilizaciones de antaño, jamás copió esquemas, cosa que sí hicieron sus compañeros de lucha, concretamente cuando se opusieron al sistema de gobierno central, para implantar el federal, calcado del estadounidense, un pueblo con mil razones diferente al nuestro..." (CORDERO, 1999).

Conocedor de los graves problemas que se le avecinaban a las incipientes naciones recién liberadas, el Libertador de América supo vislumbrar la forma en que los futuros gobiernos escaparían a dicha fragilidad. Por ello siempre acordó gran importancia a la formación del gobierno dirigido por «hombres virtuosos». Simón Bolívar, al mismo tiempo que buscaba educar al pueblo, establecía sanciones contra quienes pretendían corromperlo. Numerosos decretos firmó para contener los abusos de poder y el desenfreno de los funcionarios públicos deshonestos; medidas que llegaron hasta la pena capital. Si nuestra sociedad se corrompió no fue por falta de leyes moralizadoras, sino quizá, debido, entre otras causas, a la imposibilidad de aplicarlas con efectividad en un extenso y peligroso territorio. También hay que sumarle el hecho, en ese momento, que el mundo no conocía los avanzados sistemas de comunicación física y social de nuestro tiempo, los cuales facilitan a los gobiernos ejercer un adecuado control desde su propia sede central. Finalmente, no era un secreto para el Libertador que dentro de su grupo de seguidores, algunos directores de altos cargos, escudaban su mezquindad en nobles causas revolucionarias.

Esto fue precisamente lo que pasó en Angostu$\mathrm{ra}$, en 1819. Bolívar expuso en varios escenarios su gran proyecto de Poder Moral, el cual, garantizaría el buen funcionamiento de las instituciones creadas. Pero su proyecto fue incomprendido por algunos, seguramente los que se lucraban de los vicios administrativos, y los que seguramente impidieron que esto se aplicara. La idea del nuevo poder moral estaba llamada a fundamentar la educación y la moral de las futuras generaciones de americanos. Pero, la miopía política de sus detractores y los intereses particulares hicieron que el vicio fuera más fuerte que la virtud, abriéndole campo a la corrupción y a las malas prácticas administrativas. Hoy en día sufrimos las graves consecuencias de esta cruel miopía: la corrupción es galopante y los vicios administrativos muy arraigados en nuestras administraciones. América perdió una gran oportunidad de aplicar un buen instrumento de control social para fundamentar adecuadamente el poder político.

\section{E. Un legado de educación}

Bolívar es considerado como uno de los grandes maestros de América (PRIETO, 1902). Su personalidad va a marcar los destinos de todo un continente como se marcan los estudiantes en la escuela con las enseñanzas de grandes maestros. El "maestro de América" era uno de los hombres más preparados de su época, había leído los grandes clásicos de la filosofía griega, conocía de primera mano las enseñanzas institucionales de Rousseau, Montesquieu y Voltaire, a quienes cita reiteradamente en sus cartas a Santander y en sus discursos libertarios. En materia de educación, el libertador se inspira de Francia con sus grandes pensadores revolucionarios: Diderot, Condorcet y La Chalotais.

Estos personajes eran los mismos que inspiraron al gran Simón Rodríguez, quien fuera el maestro del Libertador y a quien Bolívar reconocía públicamente su influencia en los destinos que él quiso forjar para la América Libre. El maestro Rodríguez, era para el Libertador el fiel ejemplo de lo que debería ser el buen maestro de escuela: hombre culto, erudito y honesto. Dicho maestro debería laborar en un ambiente sano de recreación y convivencia, en donde se aprendiera por medio de la inquietud y el diálogo entre los maestros y los estudiantes. Era en la escuela en donde se comenzaba a amar la Patria y en donde se aprendía a valorar los estímulos de buen comportamiento, pero también a temer los castigos de una mala conducta. Es en este lugar en donde se cosechan los mejores frutos de la sociedad, en donde se forja la 
moral del hombre de bien y se educa para ser ciudadano.

\section{LOS FUNDAMENTOS REVOLUCIONARIOS DE LA REPÚBLICA}

\section{A. Fundamentos constitucionales continentales}

El legado ideológico de Bolívar se verá reflejado en casi todas las Constituciones y textos fundamentales de la vida política latinoamericana.

En la primera Constitución Venezolana, votada en Caracas el 21 de diciembre de 1811, primera Constitución libre y representativa que ha visto el Continente, se establece claramente el ideal bolivariano de unión entre los pueblos del continente americano. De esta forma se reafirma una ideología continental en donde todos los pueblos que fueron subyugados por la Corona española se comprometen a luchar juntos por los destinos de todos sus habitantes:

"Nos obligamos, y comprometemos a observar y cumplir inviolablemente todas y cada una de las cosas que en ella se comprenden, protestando sin embargo, alterar y mudar en cualquier tiempo estas resoluciones, conforme a la mayoría de los Pueblos de Colombia que quieran reunirse en un Cuerpo nacional para la defensa y conservación de su libertad, e independencia política, modificándolas, corrigiéndolas y acomodándolas oportunamente y a pluralidad y de común acuerdo entre nosotros mismos, en todo lo que tuviere relaciones directas con los intereses generales de los referidos Pueblos". (ZUBIRÍA, 1983).

El 15 de diciembre de 1812, en Cartagena, Simón Bolívar difunde su famosa Memoria dirigida a los ciudadanos de la Nueva Granada por un caraqueño, más conocida como el Manifiesto de Cartagena. En este, el primer documento político más importante que revela el pensamiento ideológico del libertador, se expresa: "Libertar a la Nueva Granada de la suerte de Venezuela y redimir a ésta de la que padece, son los objetos que me he propuesto en esta memoria" (DE ZUBIRÍA, 1983).

El 14 de octubre de 1813, el Cabildo de Caracas asume la representación de Venezuela, y declara a Bolívar General en Jefe de sus ejércitos, otorgándole el título de Libertador, con el cual Mérida ya lo había distinguido. Con esto se reorganiza el Gobierno y se favorece la expedición continental por la libertad de todos los pueblos de América hispana. En Decreto de Trujillo, del 15 de junio de 1813, el Libertador reitera su decisión de liberar todo el continente del colonialismo español y desde allí prepara su viaje al Caribe, en donde el 6 de septiembre de 1815 escribe su famosa Carta de Jamaica. Allí se hace un análisis de la situación política de todo el continente y se establece una estrategia de unión latinoamericana y del Caribe para luchar contra el invasor.

Al otro lado del continente, sobre todo a partir de 1816 mejoran las condiciones para la libertad de América tras el exilio napoleónico. El armamento fluye del viejo continente a precios favorables y sin contraprestaciones absurdas, lo que aumenta el pie de fuerza bolivariano contra el ejército colonial. Los industriales y mercaderes británicos, al no tener la amenaza francesa y al evidenciar la debilidad española, imponen modificaciones a la política exterior del reino británico para favorecer la expansión del comercio en América. Por ello, el gobierno inglés se ve forzado a negociar su armamento sobrante por mercancías y bienes de buenos precios que le ofrecía el nuevo continente: cacao, café, frutos y cuero.

En 1818 , los patriotas tienen cuanto necesitan en armas y material de guerra, cuentan con varias ciudades conquistadas y gobernadas militarmente, además que poseen un importante comercio y una fuerte relación diplomática con el viejo mundo.

Desde entonces comienza para Bolívar una década de gloria en donde va a liberar definitivamente a Venezuela y se apodera de toda la región Andina. Será en Angostura, con la apari- 
ción de Santander, en donde volverán a echarse los fundamentos institucionales de la República. Comienza entonces acá definitivamente el fin del desorden institucional y se conocen las primeras instituciones estatales del nuevo continente liberado: el Consejo de Estado, el Congreso de la República, la Alta Corte de Justicia, el Poder Ejecutivo y sus Secretarías o Despachos. Desde allí, se dirige a la Santa Alianza europea para que no intente apoyar a España en su deseo de reconquistar el continente; es Bolívar ahora un estadista de reconocimiento mundial.

La hazaña de Boyacá del 7 de agosto de 1819 y el control de los Andes, confirman la voluntad continental de constituir una gran Nación libre muy a la imagen de la nación europea. En el Congreso de Angostura de 1819 ya Colombia, Venezuela y Ecuador conforman un solo país y se echan las bases militares para la conquista de Perú y Bolivia.

En 1820, se da un giro a la política realista de España con el alzamiento de Riego y Quiroga, lo que obliga a Fernando VII a aceptar la Constitución liberal de 1812. Este hecho impide el envío de nuevas tropas en América e influye en el cambio de conducta en Venezuela, en donde, el pueblo comienza a alejarse progresivamente de los realistas.

Después de 1823 con la batalla de Carabobo, Venezuela queda finalmente conquistada y Simón Bolívar emprende la Campaña del Sur (182226). En esta, su última cruzada libertadora, lo acompañan tropas oficiales compuestas por venezolanos y neogranadinos. Con el gran apoyo de Antonio Anzoátegui y Antonio José de Sucre liberan Ecuador y Perú en las batallas de Pichincha del 24 mayo de 1822, de Junín del 6 agosto de 1824 y de Ayacucho del 9 diciembre de 1824 . Con estas se cierra la brecha revolucionaria por la unidad y por la democracia; comienza entonces el fin de la esclavitud y se conforman gobiernos de unidad que deban comenzar por el reparto de tierras y bienes entre los indígenas, negros y ejércitos revolucionarios.
Desde entonces Bolívar trata de consolidar una unión continental: redacta y presenta el proyecto de la Carta Fundamental para Bolivia, convoca al Congreso Anfictiónico de Plenipotenciarios que debe reunirse en Panamá de 1826, recibe a los enviados del Río de la Plata y los enviados europeos como observadores a la propuesta federal. Desde 1821, ya Bolívar había comenzado sus contactos con España, invitándola a unirse al nuevo proyecto continental para beneficio de toda Europa. Es el Congreso Anfictiónico el que reúne sus mayores esperanzas para unir el continente y así luchar contra la Santa Alianza que amenaza de apoyar España.

\section{B. Fundamentos institucionales bicentenarios}

\section{Libertad, democracia y soberanía}

La lucha libertaría de Bolívar se extiende por espacio de 20 años. En este tiempo, su principal preocupación fue la libertad de los pueblos. Sin éste elemento el continente latinoamericano nunca podría ser soberano. Para Bolívar era una exigencia de la historia el que a América se le considerara como un continente libre y soberano, pero esto no se podía lograr sin un adecuado sistema democrático que le diera al gobierno de turno toda la legitimidad que necesita el Estado.

Para Bolívar, estos tres elementos eran la trípode de una sola columna que representaba la base del poder. Para el Libertador, la soberanía reside en la universalidad de los ciudadanos, ella es inseparable del pueblo y también es imprescriptible, no se elimina por el no uso de la misma. Así lo expresó claramente en Angostura, en 1819: la voluntad del pueblo, correctamente manifestada, da origen incontrovertible a las potestades públicas:

"La continuación de la autoridad en un mismo individuo frecuentemente ha sido el término de los gobiernos democráticos. Las repetidas elecciones son esenciales en los sistemas populares, porque nada es tan peligro- 
so como dejar permanecer largo tiempo en un mismo ciudadano el poder. El pueblo se acostumbra a obedecerle y él se acostumbra a mandarlo; de donde se origina la usurpación y la tiranía. Un justo celo es la garantía de la libertad republicana, y nuestros ciudadanos deben temer con sobrada justicia que el mismo magistrado, que los ha mandado mucho tiempo, los mande perpetuamente".

En Lima, en 1824, ratifica su fe en estos principios, ordena al Consejo de Gobierno, con la neutralidad del Ejecutivo, tomar el más celoso empeño para hacer ejecutar las elecciones populares del nuevo congreso. De esta forma la ley pone al pueblo en ejercicio de la plena libertad de elegir: la de elegir en plena conciencia.

Esta convicción la ratifica en la Constitución de Bolivia del 25 de mayo de 1825:

"El proyecto de Constitución para Bolivia está dividido en cuatro poderes políticos, habiendo añadido uno más, sin complicar por esto la división clásica de cada uno de los otros. El electoral ha recibido facultades que no le estaban señaladas en otros gobiernos que se estiman entre los más liberales. Estas atribuciones se acercan en gran manera a las del sistema federal. Me ha parecido no sólo conveniente y útil, sino también fácil, conceder a los representantes inmediatos del pueblo los privilegios que más puedan desear los ciudadanos de cada departamento, provincia y cantón. Ningún objeto es más importante a un ciudadano que la elección de sus legisladores, magistrados, jueces y pastores. Los colegios electorales de cada provincia representan las necesidades y los intereses de ellas y sirven para quejarse de las infracciones de las leyes, y de los abusos de los magistrados".

\section{La división del poder}

Si para Bolívar el sistema de gobierno debía ser centralizado y unido, el poder que éste engendraba no podía sino ser dividido. Esta era, según el Libertador, la única manera de darle coordinación y equilibrio a un gobierno justo, evitando que por ambición cayera en el despotismo. En Aristóteles, Locke y Montesquieu, se inspira Bolívar para argumentar que en el poder había que distinguir funciones con áreas muy específicas. Como Montesquieu, el libertador no llega a proponer entre ellos una separación absoluta, por el contrario de lo que se trataba era de enlazar los poderes con los vínculos de la armonía que mantenga el respeto recíproco entre los diferentes órganos del Estado.

Bolívar explica muy bien en Angostura en 1819 cuál era el gobierno que él buscaba: un gobierno democrático, republicano, popular, efectivo, moralmente fuerte y capaz de sobreponerse a la anarquía y a la tiranía. Este nuevo gobierno no podía reproducir los vicios de la colonia, debía ser apto para defender y completar la Revolución. En sus discursos de Congreso, Bolívar propone su gobierno ideal:

"El sistema de gobierno más perfecto es aquel que produce mayor felicidad posible, mayor suma de seguridad social y mayor suma de estabilidad política (...) Hemos dividido como los americanos la representación nacional en dos cámaras: la de representantes y la del senado (...) El senado hereditario, repito, será la base fundamental del poder legislativo, y por consiguiente será la base de todo gobierno. Igualmente servirá de contrapeso para el gobierno y para el pueblo: será una potestad intermedia que embote los tiros que recíprocamente se lanzan estos eternos rivales.(...) Abandonemos las formas federales que no nos convienen; abandonemos el triunvirato del poder ejecutivo; y concentrándolo en un presidente, confiémosle la autoridad suficiente para que logre mantenerse luchando contra los inconvenientes anexos a nuestra reciente situación, al Estado de guerra que sufrimos y a la especie de los enemigos externos y domésticos, contra quienes tendremos largo tiempo que combatir (...) Que el poder legislativo se desprenda de las 
atribuciones que corresponden al ejecutivo; y adquiera no obstante nueva consistencia, nueva influencia en el equilibrio de las autoridades. Que los tribunales sean reforzados por la estabilidad y la independencia de los jueces; por el establecimiento de Jurados; de códigos civiles y criminales que no sean dictados por la antigüedad ni por reyes conquistadores, sino por la voz de la naturaleza, por el grito de la justicia y por el genio de la sabiduría".

El Libertador dispone de un cuarto poder solamente en dos casos: en Angostura el Poder Moral y en Bolivia el Poder Electoral. Bolívar reproduce en Angostura la forma bicameral corriente para el legislativo, pero considera que el senado debía ser hereditario. En Bolivia propone una tercera cámara denominada censores, a la cual se le asigna el poder moral propuesto en 1819. Para el Ejecutivo, en Angostura prevé un presidente electo popularmente, responsable y alternativo, un vicepresidente y ministros. Allí presenta el sistema del gabinete solidario del presidente, pero para Bolivia, extrañamente Bolívar propone la figura del presidente vitalicio.

\section{La reforma agraria}

Si algún elemento institucional ha quedado inconcluso en la construcción del Estado bolivariano, este ha sido el de la reforma agraria. Es ya sabido por todos que la distribución de la riqueza colonial era muy injusta y desigual. Pocos eran los que lo poseían todo, una gran mayoría los que no tenía nada. Los que más padecieron esta ignominia fueron los campesinos y los esclavos. Los campesinos porque siempre labraron la tierra sin pertenecerles y los esclavos porque trabajaron las minas sin nunca haber sacado el mínimo provecho de ello.

Estas porciones humanas de la sociedad nunca tuvieron acceso al comercio, ni a la propiedad ni al goce de los mínimos derechos individuales. No poseían libertad y la igualdad era solo una quimera que un hombre burgués, Antonio Nariño, vino a evocar sin mayor interés para los señores de la época. Con el esfuerzo de los esclavos, pertenencia de sus amos, se formaron haciendas y explotaciones mineras. Las leyes de Indias sobre el trabajo de los aborígenes nunca se aplicaron; las mismas autoridades encargadas de hacerlas cumplir eran las más interesadas en desconocerlas, porque ellas mismas ocupaban personal indígena en sus plantaciones.

A esto se sumaba la injusticia fiscal a la cual estaban sometidos los comerciantes. Muchos fueron los alzamientos contra la injusticia que constituyeron los Comuneros de E1 Socorro y de los Andes en Colombia, movimientos de sin tierra en el Perú, en Argentina, en México y en casi todo el continente. A estos se le acumulaban las revueltas constantes de negros e indios en contra del sistema inmoral de esclavitud y servidumbre al cual estaban sometidos. Bolívar era consciente de esta injusticia y por ello decretó desde 1817 muchas disposiciones a favor de la devolución de tierras para los indígenas y la libertad de explotación de algunas actividades como la pesca para las poblaciones negras.

Desafortunadamente, la mayor parte de las reformas agraria que decreto Bolívar llegaron a manos de militares y combatientes revolucionarios. Algunas tierras llegaron a los indígenas mediante las leyes de resguardos, pero casi ninguna llegó a las poblaciones negras, las cuales se amontonaron en palenques y asentamientos poco cultivables. Para algunos historiadores (GRIFFIN, 1969) el sistema de bonificaciones para los soldados revolucionarios no puede llamarse de ninguna manera una ley agraria. A su juicio, el número de individuos que podrían haber sido beneficiarios de la disposición bolivariana era muy bajo. Esto podría constituir la base de la dificultad manifiesta en la que se encuentra el Estado colombiano para construirse adecuadamente una nación igualitaria. Ningún gobernante, aparte de Alfonso López Pumarejo en 1930, ha retomado de forma global la ideología social revolucionaria del Libertador. Si esto se hubiera cumplido como lo deseaba el libertador, otra sería la historia de nuestro continente. 


\section{CONCLUSIÓN}

Ideológicamente nuestra República está fundamentada sobre principios sólidos de libertad e igualdad dentro de un sistema democrático. Esto ha sido la constante a dos siglos de nuestra independencia. Sin embargo, lejos estamos de haber alcanzado la construcción de la república deseada por Bolívar.

Después de la muerte de Simón Bolívar y el asesinato del Mariscal Antonio José de Sucre, Santander trató de continuar la ideología liberal de la revolución, pero hubo una reacción de los caudillos militares y la organización de dos fracciones liberales: el partido conservador y el partido liberal, más partidos de intereses personales que objetivos ideológicos opuestos. La primera constitución pos bolivariana fue la del vicepresidente José María Obando, que la denomina Constitución del Estado "republicano, electivo, alternativo y responsable", incluido un catalogo de libertades públicas. El gobierno liberal que apoyaba a Santander se divide en varias facciones ante el fusilamiento de varios hombres de confianza, el general José Sarda y el coronel Mariano París, acusados de conspiración.

Después, al momento de terminar el gobierno de Santander en 1837, bajo la presidencia de José Ignacio de Márquez, se crean dos fracciones del liberalismo: los gólgotas o radicales y los draconianos o moderados. La fracción conservadora del pensamiento de Bolívar seguirá siendo minoritaria hasta los eventos de la Constitución de 1886.

Por ello, entre 1832 y 1886 hubo una ideología liberal bastante fuerte, en donde se privilegió el libre comercio y la regionalización del territorio. Los ricos comerciantes y terratenientes de las Provincias se oponían a los tradicionales políticos de la capital, estos últimos dominados de cierta forma por la regla de tradición que imponía la iglesia católica. Por ello no fue extraño que el caudillo draconiano, el General José María Obando, se levantara en armas contra el gobierno de Márquez, seguido por los gobernadores liberales de las provincias que lo proclamaron "jefe supremo". Contra estos, se levantan los fieles a Bolívar, el general Tomás Cipriano de Mosquera y el general Pedro Alcántara Herrán. De esta victoria surgió el grupo político denominado "ministerial", de corte conservador y que hizo posible la reforma constitucional de 1843 que dio amplios poderes al ejecutivo para conjurar este tipo de revueltas. A estas ideas siguen opuestos los supremos, quienes se oponen a las ideas conservadoras de los ministeriales o casacas negras. De allí surge de forma permanente la oposición ideológica entre liberales y conservadores.

Desde entonces, podemos afirmar que comienza una "guerra" ideológica, y en cierta forma militar entre dos posiciones ideológicas opuestas: los conservadores, dirigidos por José Eusebio Caro y Mariano Ospina Rodríguez, los que defendían el orden constitucional, el centralismo, la fuerza militar y la consagración del Estado a la iglesia católica, y los liberales, quienes con la dirección de Ezequiel Rojas, defendían el libre comercio, la separación de la iglesia católica y del Estado, las libertades públicas y la descentralización.

Del Estado centro federal (1853-1886) al Estado liberal intervencionista, existen múltiples interpretaciones de la ideología revolucionaria y se preocupan más por la dominación del territorio que por el desarrollo de la justicia social.

Entre 1886 y 1930, hubo gobiernos conservadores, que se ocuparon de darle a Colombia la independencia y la soberanía que soñó el Libertador. Entre 1930 y 1946, hubo un período liberal que trató de desarrollar la reforma agraria y los derechos de los ciudadanos. Después del período dictatorial del General Rojas Pinilla (19531957), los gobiernos de turno, bajo el nombre de Frente Nacional, decidieron dividirse el Estado, y allí toda ideología política desaparece en beneficio de la burocracia y de la colonización política de las regiones. Los gobiernos que le siguen son en su mayoría liberales, salvo el de Belisario Betancur (1982-1986) y el de Andrés 
Pastrana (1998-2002). Ninguno pudo lograr la consolidación del Estado de derecho y el libre ejercicio de las libertades públicas.

\section{REFERENCIAS BIBLIOGRÁFICAS}

CORDERO CEBALLOS, José de Jesús (1999). Bolívar y la vigencia del poder moral. Concejo de publicaciones de la Universidad de los Andes. Mérida (Venezuela).

DE ZUBIRÍA, Ramón (1983). Breviario del Libertador, un esquema documental básico. Bedout editores, Cacharrería Mundial. Medellín.

GRIFFIN, Charles (1969). El período nacional en la historia del nuevo mundo. Instituto panamericano de geografía e historia. México.

MIJARES, Augusto (1998). El libertador. Caracas. Monte Ávila.
MOLINA, Carlos y otros, (2008). Historia de las ideologías políticas. P. 11. Universidad EAFIT. MEDELLÍN.

POLANCO ALCANTARA, Tomás (1997). Simón Bolívar. Ensayo de una interpretación biográfica a través de sus documentos. $4^{\mathrm{e}}$ Barcelona. EG.

PRIETO FIGUEROA, Luis Beltrán (1902). El magisterio americano de Bolívar. Editorial Arte, Caracas (Venezuela).

RUIZ GARCÍA, Miguel Ángel y otros (2008). Historia de las ideologías políticas. P. 483. Universidad EAFIT. MEDELLÍN.

SALCEDO BASTARDO, José Luis (1982). Bolívar: un continente y un destino. $12^{\mathrm{E}}$. Comité Ejecutivo del Bicentenario de Simón Bolívar, Caracas (Venezuela). 



\section{FACULTADES DE LAS VÍCTIMAS COMO SUJETOS PROCESALES EN EL SISTEMA ACUSATORIO DE CONFOR- MIDAD CON LA JURISPRUDENCIA DE LA CORTE CONSTITUCIONAL*}

\author{
Alvaro E. Márquez Cárdenas ${ }^{* *}$ \\ Universidad Militar Nueva Granada
}

Fecha de recepción: 20 de abril de 2009

Fecha de aceptación: 11 de mayo de 2009

\section{Resumen}

La Corte Constitucional desde la vigencia de la Ley 906 de 2004, ha venido consolidando y reconociendo los derechos de las víctimas en el proceso penal de tendencia acusatoria. En el presente escrito, pretendemos señalar con fundamento en esos derechos, las facultades y oportunidades procesales que tienen las víctimas y los perjudicados como sujetos procesales para actuar y participar activamente en la investigación y el juicio en defensa de sus derechos.

\section{Palabras clave}

Víctima, compensación, indemnización, autores, sujetos procesales, daño, perjuicio, derechos, verdad, impunidad, reparación.

\section{POWERS OF THE VICTIM AS A SUBJECT IN THE PROCESS OF ACCUSATORY SISTEM IN ACCORDANCE WHITH THE JURISPRUDENCE OF THE CONSTITUTIONAL COURT}

\footnotetext{
Abstract

The Constitutional Court since the existence of Act 906 of 2004, has been consolidating, and

El presente escrito es el resultado de la investigación denominada: La Conciliación preprocesal en el nuevo sistema procesal acusatorio. Línea de investigación: Derecho penal. Centro de investigaciones de la Universidad Militar Nueva Granada

** Abogado. Doctor en Derecho. Universidad Complutense de Madrid, España. Estudios de postdoctorado Universidad Carlos II de Madrid. Especialista en criminología. Instituto de criminología, U. Complutense. Master en Estudios Políticos, Universidad Javeriana, ex magistrado, Docente investigador-postgrados de la Facultad de Derecho de la Universidad Militar. Investigador Centro de investigaciones de la Universidad Militar Nueva Granada.
}

recognizing the rights of victims in the trend of adversarial criminal proceedings. In this paper, we intend to draw on the basis of such rights, powers and procedural opportunities that are victims and injured persons to act as parties to the proceedings and actively participate in the investigation and trial in defense of their rights.

\section{Keywords}

Victim, compensation, indemnity, author, subject proceedings, damages, rights, truth, impunity repair.

\section{RESULTADOS}

El sistema de protección a la víctima en el ordenamiento procesal colombiano, es decir, en el sistema acusatorio, derivado del Acto Legislativo 003 del 19 de diciembre de 2003, ha suscitado un importante debate académico frente a su implementación y desarrollo en la ley 906 de 2004.

Aunque en nuestra legislación procesal de la ley 600 de 2000 la víctima no ha estado en marginación, pues, ella puede estar representada por un abogado, se reconoce una acción civil individual, pueden ejercer derecho de petición ante el funcionario judicial con el fin de obtener información o hacer solicitudes especificas, pueden aportar pruebas, pero además aparecen otras figuras, como el tercero civilmente responsable, o la denuncia del pleito o el llamamiento en garantía, que otorgan ciertas garantías a las víctimas a efectos de que sean indemnizadas por los perjuicios que se les hubieren ocasionado como consecuencia de la realización de una conducta punible y que, incluso, en el sistema procesal acusatorio no se consagran; por lo tanto, lo que con el ordenamiento procesal penal se debe buscar es mejorar el tratamiento de las mismas, sin que ello implique desmedro alguno para el autor o participe del delito ${ }^{1}$.

SANPEDRO ARRUBLA, Julio Andrés. "La reconstrucción victimológica del sistema penal: las víctimas del delito en la reforma constitucional de la justicia penal". En revista Reforma de la justicia penal, tomo II, Bogotá, Corporación excelencia de la Justicia, 2003. pág. 103 y ss. 
Un significativo avance en materia de víctimas en nuestro país se presentó con la Sentencia C228 de 2002 de la Corte Constitucional, en el sentido de reconocer que la víctima o perjudicado con un delito no solo tiene derecho a la reparación económica de los perjuicios, como venía ocurriendo frente a la parte civil, sino que además tiene derecho a que a través del proceso penal se establezca la verdad y se haga justicia.

Dijo al respecto la Corte Constitucional con ponencia del Dr. Manuel Cepeda y el Dr. Eduardo Montealegre:

“... los derechos de las víctimas y perjudicados por un hecho punible gozan de una concepción amplia no restringida exclusivamente a una reparación económica fundada en los derechos que ellas tienen a ser tratadas con dignidad, a participar en las decisiones que las afecten y a obtener la tutela judicial efectiva del goce real de sus derechos, entre otros, y que exige a las autoridades que orienten sus acciones hacia el restablecimiento integral de sus derechos cuando han sido vulnerados por un hecho punible. Ello solo es posible si a las víctimas y perjudicados por un delito se les garantizan, a lo menos, sus derechos a la verdad, a la justicia y a la reparación económica de los daños sufridos.

De tal manera que la víctima y los perjudicados por un delito tienen intereses adicionales a la mera reparación pecuniaria. Algunos de sus intereses han sido protegidos por la constitución de 1991 y se traducen en tres derechos relevantes para analizar la norma demandada en el presente proceso:

El derecho a la verdad, esto es, la posibilidad de conocer lo que sucedió y en buscar una coincidencia entre la verdad procesal y la verdad real. Este derecho resulta particularmente importante frente a graves violaciones de los derechos humanos.

El derecho a que se haga justicia en el caso concreto, es decir, el derecho a que no haya impunidad.
El derecho a la reparación del daño que se le ha causado a través de una compensación económica, que es la forma tradicional como se ha resarcido a la víctima del delito.

Aun cuando tradicionalmente la garantía de estos tres derechos le interesen a la parte civil, es posible que en ciertos casos, esta solo este interesada en el establecimiento de la verdad o el logro de la justicia y deje de lado la obtención de una indemnización...".

Esa tendencia de mayor protección a la víctima se vio reflejada en el Acto Legislativo 03 de 2002 que en su artículo $2^{\circ}$ modificó el artículo 250 de la Carta que consagra las funciones de la Fiscalía General de la Nación y que en sus numerales 1,6 y 7 dice textualmente:

1. Solicitar al juez que ejerza las funciones de control de garantías las medidas necesarias que aseguren la comparecencia de los imputados al proceso penal, la conservación de la prueba y la protección de la comunidad, en especial, de la víctimas.

2. Solicitar ante el juez de conocimiento las medidas judiciales necesarias para la asistencia a las víctimas, lo mismo que disponer el restablecimiento del derecho y la reparación integral a los afectados con el delito.

3. Velar por la protección de las víctimas, los jurados, los testigos y demás intervinientes en el proceso penal, la ley fijará los términos en que podrán intervenir las víctimas en el proceso penal y los mecanismos de justicia restaurativa.

Lo que pretende con el redescubrimiento es generar un equilibrio en la relación procesal, que así como se tiene en cuenta al procesado se tenga en cuenta los derechos y garantías de las víctimas del delito, permitiendo la redefinición de los roles que desarrollan las personas dentro del drama criminal y posteriormente en el proceso 
de la investigación penal ${ }^{2}$. Hay que cambiar el criterio según el cual los únicos protagonistas en proceso penal son el Estado y el delincuente; porque la víctima tiene mucho que decir, hacer y contribuir a la solución del conflicto penal. De esta manera las víctimas con voz propia y sin que nadie la sustituya son el camino obligado para la solución alternativa al proceso penal, adquiriendo la posición que les corresponde en la tragedia criminal.

Una vez reconocidos los derechos de la víctima en forma amplia por parte del Corte Constitucional, la jurisprudencia de esta alta Corporación inició con la sentencia C-454 de 2006, al determinar los alcances de las facultades de las víctimas para actuar en el proceso penal, así, se destaca la de solicitar pruebas en la audiencia preparatoria regulada en el artículo 357 de la Ley 906 de 2004 y destacó que la omisión del legislador al no incluir a las víctimas dentro de los actores procesales que podían hacer solicitudes probatorias en la audiencia preparatoria, era contraria a la Carta. Posteriormente en la sentencia C- 209 de 2007, dejó claro, que las víctimas no son meros intervinientes o sólo intervinientes especiales, sino verdaderos sujetos procesales o partes procesales con todos sus derechos en igualdad de condiciones o equivalentes a los que en el proceso acusatorio tiene el procesado, el fiscal o el ministerio público en su intervención procesal. En este acápite nos referimos a las facultades que, por vía jurisprudencial de la Corte Constitucional, se le han reconocido a las víctimas para participar en las audiencias públicas en todo el proceso penal y en especial en el debate probatorio, precisando también sus limitaciones en su intervención en el juicio oral.
2 Gaviria Londoño, Vicente Emilio. La víctima en el sistema acusatorio del nuevo Código de procedimiento penal. En revista Derecho penal y criminología. Volumen XXIV, Número 74, Enero-diciembre de 2003. Homenaje a Fernando Hinestrosa. Universidad Externado de Colombia. Bogotá, 2003. Pág. 93 y ss.

\section{FACULTADES DE LA VÍCTIMA PARA SOLICITAR MEDIDAS DE ASEGURAMIENTO Y DE PROTECCIÓN EN EL PROCESO PENAL}

En la sentencia C-805 de 2002, ${ }^{3}$ la Corte reconoció el derecho de las víctimas del delito a solicitar el control de legalidad de la decisión del fiscal de no imponer medidas de aseguramiento y en la sentencia C-209 de 2007, destacó la relevancia que tienen, para las víctimas, las determinaciones relacionadas con la imposición de medidas de aseguramiento al imputado y reconoció a las víctimas el derecho de controlar las omisiones, inacciones o decisiones que afecten sus derechos. En esa oportunidad expresó la Corte que la decisión de imponer la detención preventiva como medida de aseguramiento constituye un asunto de especial relevancia para la parte civil durante el proceso penal, por las siguientes razones:

a) Desde una perspectiva estrictamente patrimonial, es decir, atendiendo el interés resarcitorio de la parte civil, una determinación de esta naturaleza repercute en la posibilidad de solicitar el embargo y secuestro de bienes, dado que según el artículo 60 del

3 Corte Constitucional, Sentencia C-805 de 2002 MP. Manuel José Cepeda Espinosa y Eduardo Montealegre Lynett, salvamento de voto conjunto de Alfredo Beltrán Sierra y Álvaro Tafur Galvis. Ver la aclaración de voto del Magistrado Manuel José Cepeda Espinosa, a la sentencia C-456 de 2006, MP. Alfredo Beltrán Sierra -que declaró inexequible las expresiones "...por una sola vez" y "Contra esta decisión no procede recurso alguno.", contenidas en el artículo 318 de la Ley 906 de 2004, que regula la solicitud de revocatoria de la medida de aseguramiento - se resaltó lo siguiente: "A fin de que los derechos de las víctimas no queden desprotegidos por la solicitud reiterada de un imputado para que se revoque o sustituya la medida de aseguramiento restrictiva de la libertad, en cada caso concreto el juez de control de garantías deberá constatar que (i) efectivamente hayan desaparecido los requisitos que establece el artículo 308 de la Ley 906 de 2004, para la procedencia de la medida de aseguramiento; y (ii) que la supuesta desaparición de los requisitos esté sustentada en hechos nuevos de entidad suficiente para mostrar que indudablemente desaparecieron las circunstancias que justificaron la medida." 
CPP, ello solamente procede si existe medida de aseguramiento.

b) Cuando el fiscal no ordena la detención preventiva a pesar de que se reúnen los requisitos para hacerlo, los objetivos de la medida pueden verse anulados, ya sea por la no comparecencia del imputado en etapas subsiguientes, por la destrucción de elementos probatorios valiosos, o por la obstaculización (directa o indirecta) de la investigación. Sin duda todo ello afecta considerablemente los derechos a la verdad y a la justicia, de los cuales también es titular la parte civil, y que según fue indicado no son menos importantes que los derechos de contenido patrimonial.

c) En algunos eventos la gravedad de los hechos, sumada a la trascendencia de la decisión, demandan del Estado una actitud extremadamente rigurosa a fin de garantizar que el imputado no eluda el funcionamiento de la administración de justicia. Aquí la parte civil (con independencia de que sean víctimas o perjudicados), debe estar plenamente autorizada para cuestionar los yerros de las autoridades judiciales en las diferentes etapas del proceso.

d) Adicionalmente, tampoco puede desconocerse que la búsqueda de la verdad y la realización de la justicia son derechos íntimamente vinculados con el principio de legalidad, la observancia del debido proceso, la prevalencia del derecho sustancial y el derecho a la tutela judicial efectiva, en cabeza no sólo del sindicado o del Ministerio Público, sino también de la parte civil como sujeto procesal ${ }^{4}$.

Para la Corte los fines de la detención preventiva revisten significativa importancia para asegurar el pleno ejercicio de los derechos de la parte civil, razón por la cual debe ser tratada con criterios de igualdad frente a los mecanis-

\footnotetext{
C- 805 de 2002
}

mos jurídicos con que cuentan los demás sujetos procesales para controvertir las decisiones que llegaren a adoptarse al respecto. Si bien el control judicial de legalidad de la medida de aseguramiento, así como de las decisiones que afecten la propiedad, posesión, tenencia o custodia de bienes, constituye una garantía para el imputado y el Ministerio Público, de ella no puede estar excluida la parte civil, por cuanto también constituye una prerrogativa en su favor y frente a sus intereses. En consecuencia, la Corte declaró la constitucionalidad de la norma, pero en el entendido que el control de legalidad también puede ser solicitado por dicho sujeto procesal y el Ministerio Público, frente a la abstención de dictar la medida, toda vez que en ese sentido se configura una omisión legislativa contraria al ordenamiento superior.

En sentencia C-209 de 2007, destaca la Corte que la solicitud de medidas de aseguramiento o de protección ante el juez de control de garantías o ante el juez de conocimiento, según corresponda, tal como ha sido diseñada en la Ley 906 de 2004, sólo puede hacerla el fiscal. Esta fórmula pretende desarrollar el deber de protección de las víctimas establecido en el artículo 250, numeral 7 de la Carta, en concordancia con el literal b) del artículo 11 de la Ley 906 de 2004.

Para el Tribunal, la fórmula escogida por el legislador deja desprotegida a la víctima ante omisiones del fiscal, o ante circunstancias apremiantes que puedan surgir y frente a las cuales la víctima cuente con información de primera mano sobre hostigamientos o amenazas recibidas que hagan necesaria la imposición de la medida correspondiente, o sobre el incumplimiento de la medida impuesta, o la necesidad de cambiar la medida otorgada. Esto se aplica tanto a las medidas de aseguramiento como a las medidas de protección en sentido estricto.

Esta omisión excluye a la víctima como interviniente especial, que por estar en mejores condiciones para contar con información de primera mano sobre la necesidad de medidas de pro- 
tección o aseguramiento podría efectivamente solicitar al juez competente la medida correspondiente requerida.

Permitir la solicitud de medidas de aseguramiento o de protección directamente ante el juez competente por la víctima, sin mediación del fiscal, no genera una desigualdad de armas, no altera los rasgos fundamentales del sistema penal con tendencia acusatoria, ni implica una transformación del papel de interviniente especial que tiene la víctima dentro de este sistema procesal penal. Antes bien, asegura en mayor grado la adecuada protección de la vida, integridad, intimidad y seguridad de la víctima, de sus familiares y de los testigos a favor, así como de sus derechos a la verdad, a la justicia y a la reparación ${ }^{5}$.

Del anterior planteamiento para la Corte, esta omisión entraña el incumplimiento por parte del legislador del deber de configurar una intervención efectiva de la víctima en el proceso penal, en la medida que la deja desprotegida en circunstancias apremiantes o ante la omisión del fiscal en el cumplimiento de su deber de proteger a las víctimas y testigos de posibles hostigamientos o amenazas, y de solicitar las medidas necesarias para promover los fines previstos en el artículo 308 de la ley, los cuales guardan estrecha relación con los derechos de la víctima a la verdad y a la justicia.

Por lo anterior, el Tribunal declararó la exequibilidad del artículo 306, del artículo 316 y del artículo 342 de la Ley 906 de 2004, en el entendido que la víctima también puede acudir directamente ante el juez competente, ya sea el de control de garantías o el de conocimiento, según corresponda, a solicitar la medida respectiva.

C-209 de 2007. Para la Corte esta omisión genera además una desigualdad en la valoración de los derechos de la víctima, al dejarla desprotegida en circunstancias en las que deba acudirse urgentemente ante el juez competente para solicitar la adopción de una medida de protección o aseguramiento, o la modificación de la medida inicialmente otorgada.
Lo anterior no significa que el juez competente, al recibir de manera directa la solicitud de la víctima en el sentido que se imponga una medida de aseguramiento o una medida de protección específica, deba proceder a dictarla sin seguir el procedimiento señalado en las normas aplicables. Así, por ejemplo, en el caso de las medidas de aseguramiento debe previamente escuchar al fiscal, a la defensa y al Ministerio Público, como lo exige el propio artículo 306 acusado.

\section{FACULTAD DE LAS VÍCTIMAS PARA SOLICITAR LA PRÁCTICA DE PRUEBAS ANTICIPADAS}

En materia de facultades probatorias de la víctima, los artículos 284, 344, 356, 357, 358, 359, 371, 378, 391 y 395 de la Ley 906 de 2004, que tratan sobre las pruebas fueron demandadas alegando inconstitucionalidad de las mismas, con fundamento en que le impedían a la víctima participar en el debate probatorio y en el esclarecimiento de la verdad, al no permitir que solicitaran o controviertan los elementos materiales probatorios aportados por las partes en las distintas etapas de la actuación penal donde está previsto el debate probatorio.

La Corte Constitucional en sentencia C-209 de 2007, en estimó que efectivamente el artículo 284 , en su numeral 2, excluye a la víctima de los actores procesales que pueden solicitar la práctica de pruebas anticipadas para lograr el esclarecimiento de los hechos, de las circunstancias de su ocurrencia, la determinación de los responsables, de la magnitud de los daños sufridos y el esclarecimiento de la verdad.

Para el alto Tribunal, en el caso de la norma del 284 entraña un incumplimiento, por parte del legislador, del deber de configurar una verdadera intervención de la víctima en el proceso penal que le impide asegurar el derecho a la verdad y del derecho de las víctimas consagrado en el literal d) del artículo 11 de la Ley 906 de 2004. Por lo anterior, esta omisión resulta inconstitucional y en consecuencia, a la luz del cargo analizado, 
condicionó la constitucionalidad del numeral 2 del artículo 284 de la Ley 906 de 2004, en el entendido que la víctima también puede solicitar la práctica de pruebas anticipadas ante el juez de control de garantías ${ }^{6}$.

\section{FACULTAD PARA SOLICITAR EL DESCUBRIMIENTO DE LAS PRUEBAS}

En cuanto a las expresiones "la Fiscalía" y la "defensa" empleadas en el inciso segundo del artículo 344 de la Ley 906 de 2004, la Corte estimó que éstas no podian analizarse aisladamente sino que es necesario situarlas en el contexto de toda la disposición para comprender su sentido normativo ${ }^{7}$. Por ello, en el juicio se analizó sobre todo el artículo 344, por el cargo analizado. Efectuada dicha integración normativa estimó la Corte que: la norma excluye a la víctima de los actores procesales que pueden solicitar el descubrimiento de las pruebas ${ }^{8}$.

Para la Corte, esta omisión genera una desigualdad injustificada entre los distintos actores

\footnotetext{
C- 209 de 2007.

En este evento, la integración normativa procede bajo la primera hipótesis señalada en la sentencia C-320 de 1997, MP. Alejandro Martínez Caballero. Según esa sentencia, la integración de unidad normativa sólo procede de manera excepcional en tres eventos: (1) "cuando un ciudadano demanda una disposición que, individualmente, no tiene un contenido deóntico claro o unívoco, de manera que, para entenderla y aplicarla, resulta absolutamente imprescindible integrar su contenido normativo con el de otra disposición que no fue acusada." (2) "Cuando la disposición cuestionada se encuentra reproducida en otras normas del ordenamiento que no fueron demandadas." Y (3) "pese a no verificarse ninguna de las hipótesis anteriores, la norma demandada se encuentra intrínsecamente relacionada con otra disposición que, a primera vista, presenta serias dudas de constitucionalidad." Sobre el tema de integración normativa ver también, entre muchas otras, las sentencias C-357 de 1999, MP. José Gregorio Hernández Galindo; C-539 de 1999 MP. Eduardo Cifuentes Muñoz, C-781 de 2003, MP. Clara Inés Vargas Hernández; C-227 de 2004, MP. Manuel José Cepeda Espinosa; C-271 de 2003, MP. Rodrigo Escobar Gil; C-409 de 2004, MP. Alfredo Beltrán Sierra; C-538 de 2005, MP. Marco Gerardo Monroy Cabra; C-536 de 2006, MP. Humberto Antonio Sierra Porto.
}

$8 \quad$ C-209 de 2007. del proceso penal en las etapas previas al juicio; y al igual que en el caso de las solicitudes probatorias reguladas por el artículo 357 de la Ley 906 de 2004; impide a la víctima asegurar el esclarecimiento de la verdad en consecuencia, condicionó la exequibilidad del artículo 344 de la Ley 906 de 2004, en el entendido de que la víctima también puede solicitar el descubrimiento de un elemento material probatorio específico o de evidencia física específica.

\section{FACULTAD PARA HACER OBSERVACIONES SOBRE EL DESCUBRIMIENTO DE ELEMENTOS PROBATORIOS}

En este aparte de la sentencia el juicio recayó sobre el artículo 356. Al respecto, para la Corte la norma excluye a la víctima de los actores procesales que pueden participar en la audiencia preparatoria y hacer observaciones sobre el descubrimiento de elementos probatorios y la totalidad de las pruebas que se harán valer en la audiencia del juicio oral.

Consideró el Tribunal que no se observa una razón objetiva que justifique la exclusión de la víctima de esta facultad, como quiera que su participación en esta etapa previa al juicio oral, sólo tiene como finalidad el descubrimiento de elementos probatorios, pero no su contradicción o su práctica, por lo cual no conlleva una modificación de los rasgos estructurales del sistema penal, no altera la igualdad de armas, ni modifica la calidad de la víctima como interviniente especialmente protegido; Esta omisión, dijo la Corte, genera una desigualdad injustificada entre los distintos actores del proceso penal en la audiencia preparatoria, en consecuencia, declaró la exequibilidad del artículo 356 de la Ley 906 de 2004, en el entendido de que la víctima también puede hacer observaciones sobre el descubrimiento de elementos probatorios y de la totalidad de las pruebas que se harán valer en la audiencia del juicio oral ${ }^{9}$.

Ibidem 


\section{FACULTAD PARA SOLICITAR LA EXHIBICIÓN DE LOS ELEMENTOS MATERIALES PROBATORIOS}

En relación con la expresión "a solicitud de las partes" usada en el artículo 358 de la Ley 906 de 2004, la Corte considera que la norma excluye a la víctima de los actores procesales que pueden solicitar la exhibición de los elementos materiales probatorios y evidencia física, con el fin de conocerlos y estudiarlos.

Esta omisión, para los magistrados, genera una desigualdad injustificada entre los distintos actores del proceso penal en la audiencia preparatoria y en consecuencia, declaró la constitucionalidad del artículo 358 de la Ley 906 de 2004, en el entendido que la víctima también puede hacer dicha solicitud ${ }^{10}$.

\section{FACULTAD PARA SOLICITAR LA EXCLUSIÓN, EL RECHAZO O LA INADMISIBILIDAD DE LOS MEDIOS DE PRUEBA}

En relación con la expresión "las partes y el Ministerio público" contenida en el inciso primero del artículo 359 de la Ley 906 de 2004 se razono que la norma no incluye a la víctima dentro de los actores procesales que pueden solicitar la exclusión, el rechazo o la inadmisibilidad de los medios de prueba, en consecuencia, estimó la constitucionalidad del inciso primero del artículo 359 de la Ley 906 de 2004, en el entendido que la víctima también puede solicitar la exclusión, el rechazo o la inadmisibilidad de los medios de prueba ${ }^{11}$.

\section{FACULTADES DE LA VÍCTIMA EN RELACIÓN CON LA APLICACIÓN DEL PRINCIPIO DE OPORTUNIDAD}

Siguiendo las orientaciones del artículo 250 de la Carta, la Fiscalía General de la Nación, por regla general y en virtud del principio de lega- lidad, está obligada a ejercer la acción penal, el mismo artículo 250 superior permitió que excepcionalmente pudiera renunciar a la persecución penal en aplicación del principio de oportunidad.

En la sentencia C-873 de $2003,{ }^{12}$ se señala como uno de los rasgos característicos del sistema penal con tendencia acusatoria instaurado mediante el Acto Legislativo No. 03 de 2002 y desarrollado en la Ley 906 de 2004, el poder de disposición del proceso penal en los siguientes términos:

"El poder de disposición del proceso también fue modificado en cuanto a su alcance por el constituyente derivado de 2002, ya que se consagró a nivel constitucional el principio de oportunidad, por oposición al principio de legalidad. El principio de oportunidad ha sido reconocido en múltiples ordenamientos penales del mundo, y se basa en el postulado de que la acusación penal requiere no sólo que exista suficiente mérito para acusar por razones fácticas y jurídicas, sino que no existan razones de oportunidad para archivar el proceso, esto es, razones válidas por las cuales el Estado puede legítimamente optar por no perseguir penalmente una determinada conducta, en los "casos que establezca la ley" y "dentro del marco de la política criminal del Estado" ${ }^{13}$. Se trata de una previsión constitucional de las hipótesis en las cuales procede archivar la investigación, las cuales serán reguladas en detalle por la ley. El Legislador también deberá regular el alcance del control judicial de lega-

Sentencia C-873 de 2003, MP. Manuel José Cepeda Espinosa, con salvamento de voto del magistrado Jaime Araujo Rentaría. Salvamento y aclaración de voto Magistrados Alfredo Beltrán Sierra y Álvaro Tafur Galvis.

13 La Corte Constitucional aceptó el principio de oportunidad tratándose de juicios ante el Congreso. Ver sentencia SU-062 de 2001, MP. Eduardo Montealegre Lynett, en la cual se expresó: "es posible que el Congreso se abstenga de formular acusación por razones de conveniencia, en aquellos casos en que la ponderación de bienes jurídicos constitucionales le permita concluir que resulta más benéfico para la estabilidad institucional una exoneración de responsabilidad, que un juicio de consecuencias imprevisibles.(...)". 